\title{
Cysteine Duality Effect on the Corrosion Inhibition and Acceleration of 3003 Aluminium Alloy in a $2 \%$ NaCl Solution
}

\author{
Brahim El Ibrahimi, 'Aziz Jmiai, Aziza Somoue, Rachid Oukhrib, \\ Mohamed Chadili, Souad El Issami and Lahcen Bazzi \\ Applied Chemistry-Physic Team, Faculty of Sciences, University of Ibn Zohr, \\ P.O. Box 8106, Cité Dakhla, Agadir, Morocco
}

Received December 1, 2017; accepted January 21, 2018

\begin{abstract}
Cysteine's action on 3003 aluminum alloy dissolution in a $2 \% \mathrm{NaCl}$ solution, at different $\mathrm{pH}$ values, has been investigated. Weight-loss measurements, potentiodynamic polarization and electrochemical impedance at OCP were performed. The surface morphology was analyzed by SEM. The main results showed that the alloy underwent severe corrosion at 2 and $11 \mathrm{pH}$ values, as compared to at 5 and $8 \mathrm{pH}$ values. Furthermore, a duality effect of cysteine was noted, as it acted as a corrosion inhibitor or accelerator, depending on its concentration, and on the solution's $\mathrm{pH}$ value. This particular behavior can be related to the instability of the formed film adsorbed onto the metal surface. All these findings show the high complexity of cysteine action on 3003 aluminum alloy, under the investigated conditions.
\end{abstract}

Keywords: cysteine, AA3003, corrosion, $\mathrm{pH}$ and $2 \% \mathrm{NaCl}$.

\section{Introduction}

With an annual world consumption of 25 million tons, aluminum is the leader in the metallurgy of non-ferrous metals [1]. The development of applications for aluminum and its alloys, especially in the fields of transport, building, electrical engineering and packaging, can be attributed to several of its useful properties [2]. The most important feature of aluminum is its resistance to corrosion, due to its capability to form a protective film (i.e., $\mathrm{Al}_{2} \mathrm{O}_{3}$ ) on its surface. This corrosion resistance, however, easily deteriorates in acidic and basic media. The presence of chloride ions in a medium, especially in seawater or marine atmosphere conditions, is disadvantageous to aluminum and its alloys, as it produces pitting in the oxide film, thus reducing its resistance to corrosion [1].

Many efforts have been devoted to avoid this problem. One of the most used methods is to modify the electrolyte composition, by adding corrosion inhibitors [3]. For a long time, the new compounds were found to act as effective corrosion

\footnotetext{
* Corresponding author. E-mail address: brahimmhm@gmail.com
} 
inhibitors, and were object of several investigations. However, due to strict protocols imposed by environmental organizations, for the use and discharge of corrosion inhibitors, in various countries, since the last two decades [4] investigators have also added an environmental compatibility viewpoint of inhibitors to their researches aims [5]. As B.E. Amitha Rani et al. [6] and G. Gece [7] cited in their reviews, some researchers have reported the fruitful use of some naturally occurring substances and drugs, to safely inhibit the corrosion of metallic materials in various corrosive media.

Amino acids are nontoxic, biodegradable and soluble in aqueous media, easy to produce with purities greater than 99\% and relatively cheap [8-10]. These properties have attracted many investigators in the world to explore amino acids capacity to act as eco-friendly corrosion inhibitors for various metals, in different aggressive media [11]. For example, magnesium alloys in a phosphate saline solution ( $\mathrm{pH} 7.4$ ) [12], zinc in $0.05 \mathrm{M}$ and $0.1 \mathrm{M} \mathrm{HCl}$ [13], tin in tartaric acid [14], Pb-Ca-Sn alloy in sulfuricd acid [8], aluminum alloy (AA6063) in a deaerated carbonate solution [15], iron in citric acid [16], and copper in a deaerated $\mathrm{H}_{2} \mathrm{SO}_{4}$ solution [17].

Cysteine is a sulfur containing $\alpha$-amino acid, which has three dissociable protonation sites $\left(\mathrm{pK}_{\mathrm{SH}}=10.25, \mathrm{pK}_{\mathrm{NH} 3}{ }^{+}=8.16\right.$ and $\mathrm{Pk}_{\mathrm{COOH}}=1.91$ (see Fig. 1)). In an aqueous solution, the ionization of this amino acid depends on the solution's pH [18-20]. Based on the presence of three different heteroatoms (i.e., $\mathrm{S}, \mathrm{N}$ and $\mathrm{O}$ ) in its molecular structure, cysteine has the potential to become a good corrosion inhibitor [21-23]. In his paper, N.O. Eddy [23] attributed the high corrosion inhibition of cysteine, for mild steel in $0.1 \mathrm{M} \mathrm{H}_{2} \mathrm{SO}_{4}$ (compared to serine, amino butyric acid, threonine, alanine, valine, phenylalanine, tryptophan and tyrosine), to the presence of thiol and hydroxyl functional groups. D.Q. Zhang et al. [24] conducted a comparative study between cysteine, alanine and benzotriazole (BTA). They noted that cysteine showed the best inhibition efficiency towards anodic copper dissolution in an aerated $0.5 \mathrm{M}$ hydrochloric acid solution.

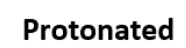

$\left(\mathrm{RSH}_{2}{ }^{+}\right)$<smiles>[NH3+][C@@H](CS)C(=O)O</smiles>

Zwitterion

(RSH)

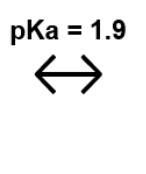<smiles>[NH3+][C@@H](CS)C(=O)[O-]</smiles>

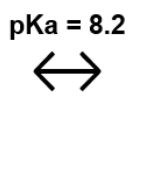

Deprotonated (I)

(RS)

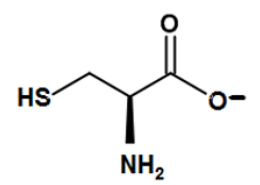

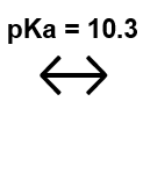

Deprotonated (II)

$\left(\mathrm{RS}^{2}\right)$

Figure 1. Cysteine forms dependent on $\mathrm{pH}$ medium.

However, several authors point out that the inhibition effect of amino acid compounds does not only depend on their chemical and electronic structures, but also on the solution's pH [25-29]. For instance, D.J. Kalota et al. [26] found that, at a $\mathrm{pH}$ value lower than 9.5, aspartic acid appeared to catalyze (accelerate) corrosion and, above this $\mathrm{pH}$ value, it acted as a good corrosion inhibitor for steel. In another study [27], it was found that cysteine activated the corrosion 
process in acidic $(\mathrm{pH} 2)$ and neutral media, but exhibited a protective effect in basic media ( $\mathrm{pH} 11)$ for lead metal.

As a representative of 3000 series aluminum alloys, AA3003 aluminum alloy has a wide range of industrial applications, being used in heat exchangers, storage tanks, drawn and spun parts manufacturing, and so on. This multicomponent alloy contains $\mathrm{Mn}, \mathrm{Fe}, \mathrm{Si}, \mathrm{Cu}$ and $\mathrm{Zn}$. For these reasons, the aim of the present work was to investigate the influence of $\mathrm{pH}$ values on the inhibition property of cysteine at different concentrations, for AA3003 aluminum alloy corrosion in a $2 \% \mathrm{NaCl}$ solution.

\section{Experimental details \\ Materials and solutions}

Materials used for this work were of a 3003 aluminum alloy (AA3003 notation will be herein subsequently used) sheet. All reagents used in this work were of Analar grade, and distilled water was used to prepare the solutions. The test solutions were prepared by dissolving an appropriate mass of L-cysteine hydrochloride monohydrate (Fuka ${ }^{\circledR}$ ) in a $2 \% \mathrm{NaCl}$ (Analytical Reagent ${ }^{\circledR}$ ) solution. The $\mathrm{pH}$ values $(2,5,8$ and 11$)$ of the $2 \% \mathrm{NaCl}$ solutions, without and with different cysteine concentrations $\left(10^{-3}, 5 \times 10^{-3}\right.$ and $\left.10^{-2} \mathrm{M}\right)$, were adjusted by using an analytical-grade reagent of hydrochloric acid $(\mathrm{HCl})$ and sodium hydroxide $(\mathrm{NaOH})$. All of the $\mathrm{pH}$ measurements were made by a Jenway® (3540) type $\mathrm{pH}$-meter, with a precision of \pm 0.01 .

\section{Weight loss method}

The sheet was mechanically pressed cut into similar coupons of dimensions $1.7 \times$ $1.8 \times 0.2 \mathrm{~cm}$. Before measuring, all tested AA3003 coupons were mechanically polished using emery paper of 800 and 1200 grade, degreased with acetone, washed with distilled water, dried in the air, and then weighed using an electronic SWISSQUALITY® (Precisa 125A) balance. Then, by using a fishing wire, each coupon was completely immersed in $75 \mathrm{~mL}$ of the tested solution (in cysteine absence and presence). After 24 hours of immersion at $25 \pm 1{ }^{\circ} \mathrm{C}$, each coupon was rinsed with distilled water and dried before re-weighing. Four tests were conducted for each experiment.

\section{Electrochemical methods}

The same tested piece was used to prepare the working electrode for the electrochemical study, which was appropriately cut to obtain a rod, and then was mounted into glass tubes by a two-component epoxy resin (Araldit $囚$ ), leaving a surface area of $0.12 \mathrm{~cm}^{2}$ with the contact solution. For electrochemical tests, it was used a three electrode all-glass cell with double wall thermostats, with a platinum $(\mathrm{Pt})$ counter electrode and saturated calomel reference electrode (SCE). Before each electrochemical experiment, the working electrode surface was mechanically polished using emery paper of 1200 grade, washed with distilled water, and quickly transferred to an electrochemical cell that contained the tested solution. 
The potentiodynamic polarization (PP) and electrochemical impedance spectroscopy (EIS) measurements were conducted by using a VoltaLab® (PGZ301) potentiostat/galvanostat and VoltaMaster 4 as control software. Before each PP or EIS experiments, the open circuit potential (OCP) of the working electrode was measured as a function of time. It was found that a duration of 45 min was appropriate to reach a quasi-stationary value for potential $\left(\mathrm{E}_{\mathrm{ocp}}\right)$; afterwards, EIS measurements were performed at this potential, with a d10 mV amplitude of the superimposed AC-signal, and the applied frequency ranged from $100 \mathrm{KHz}$ to $50 \mathrm{mHz}$. The anodic and cathodic polarization experiments were performed at a scan rate of $1 \mathrm{mV} \mathrm{s}^{-1}$ between two potentials, which depended on the $\mathrm{pH}$ value of the tested solution. To achieve reproducibility, each electrochemical experiment was carried out at least 4 times (especially, at near neutral $\mathrm{pH}$ values). The EIS data were analyzed with software based on a simplex parameter regression called ZSimpWin 3.1® software. All experiments were carried out in a stagnant natural aerated solution, at $25 \pm 1{ }^{\circ} \mathrm{C}$, using a water thermostat (IKA® - WERE, EH4 basic).

\section{Surface morphology analysis}

The surface morphology of the AA3003 specimens (before and after being immersed in a $2 \% \mathrm{NaCl}$ solution for one day, without and with $5 \times 10^{-3} \mathrm{M}$ of cysteine, both at 2 and $11 \mathrm{pH}$ values, at $25 \pm 1{ }^{\circ} \mathrm{C}$ ) was observed by a JEOL JSM ${ }^{\circledR}$ - 6480 LV scanning electron microscope.

\section{Results and discussion \\ Weight loss method}

A comparison of the AA3003 corrosion rates (expressed in $\mathrm{mg} \mathrm{cm}^{-2}$ day $^{-1}$ ), after an immersion time of one day, without cysteine, is shown in Fig. 2 (a). The corrosion rate $\left(\mathrm{W}_{\text {corr }}\right)$ over the exposure period was calculated using the following equation:

$$
W_{\text {corr }}=\frac{m_{1}-m_{2}}{\text { A.t }}
$$

where $\mathrm{m}_{1}$ and $\mathrm{m}_{2}$ are the weight $(\mathrm{mg})$ before and after immersion in the test solution, $\mathrm{A}$ is the specimen area $\left(\mathrm{cm}^{2}\right)$, and $\mathrm{t}$ is the exposure time (day). As it can be seen from Fig. 2 (a), the corrosion rate of AA3003 samples was high (uniform corrosion type) at the extreme tested $\mathrm{pH}$ values of saline media (i.e., $\mathrm{pH} 2$ and 11). However, in near neutral solutions (i.e., 5 and $8 \mathrm{pH}$ values), the corrosion rate was lower compared to the previous tested media's $\mathrm{pH}$, because, in these media, and in chloride ions presence, the corrosion mainly occurs through a localized attack. For this purpose, and due to the used balance precision, we have studied cysteine effect by this method, only for acidic and alkaline extreme $\mathrm{pH}$ values of $2 \% \mathrm{NaCl}$ solutions. According to the saline solution's $\mathrm{pH}$ value, in cysteine absence, the corrosion rate increased as follows: $\mathrm{W}_{\text {corr }}(\mathrm{pH} 2)>\mathrm{W}_{\text {corr }}$ $\left(\mathrm{pH} \mathrm{11)}>\mathrm{W}_{\text {corr }}(\mathrm{pH} 5)>\mathrm{W}_{\text {corr }}(\mathrm{pH}\right.$ 8) (Fig. 2). 

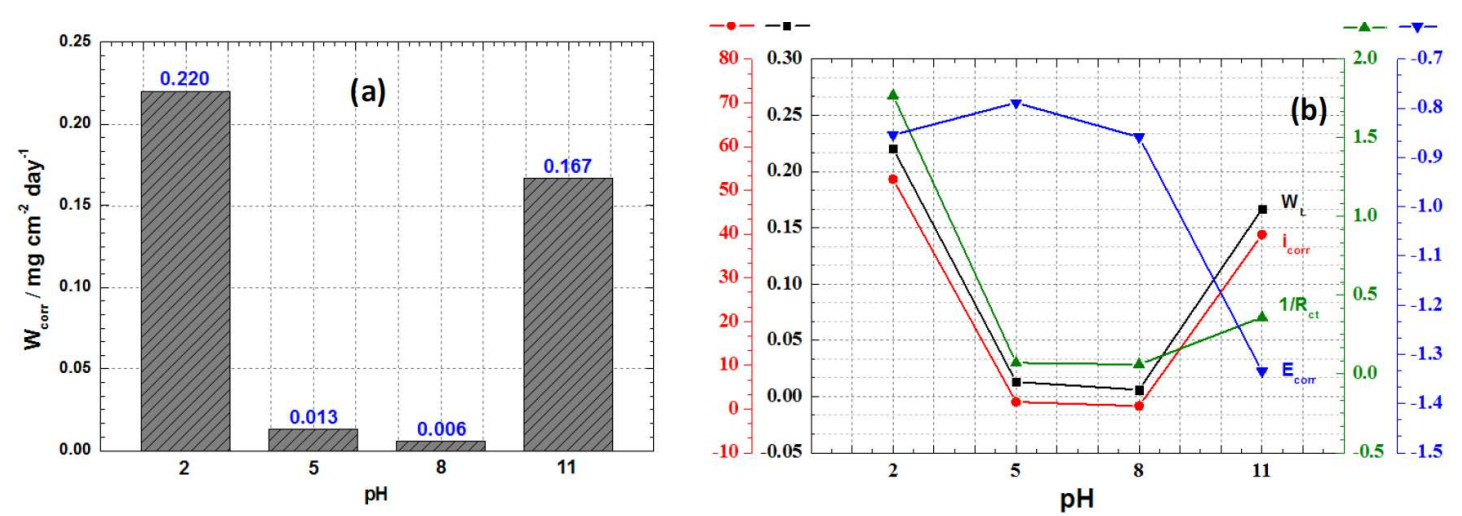

Figure 2. (a) Corrosion rate $\left(\mathrm{W}_{\text {corr }}\right)$ of $\mathrm{AA} 3003$ samples at different $\mathrm{pH}$ values of $2 \%$ $\mathrm{NaCl}$ solutions (at $25 \pm 1{ }^{\circ} \mathrm{C}$ ). (b) Summary of obtained results by used electrochemical techniques for $\mathrm{AA} 3003$ in $2 \% \mathrm{NaCl}$ without cysteine (blank solution), at tested $\mathrm{pH}$ values for $(\boldsymbol{\square})$ corrosion rate $\left(\mathrm{mg} \mathrm{cm}^{-2} \mathrm{day}^{-1}\right),(\nabla)$ corrosion potential $(\mathrm{V}),(\bullet)$ corrosion current density $\left(\mu \mathrm{A} \mathrm{cm}{ }^{-2}\right)$, and $(\Delta)$ total charge transfer resistance inverse $(\mathrm{Kohm})$ parameter at $25 \pm 1^{\circ} \mathrm{C}$.

The inhibition efficiency percentage ( $\left.\mathrm{IE}_{\mathrm{w}}, \%\right)$ obtained by weight loss method, for 2 and $11 \mathrm{pH}$ values of the tested saline solution, was calculated by using the following formula:

$$
\mathrm{IE}_{\mathrm{w}}(\%)=\left(1-\frac{\mathrm{W}_{\text {corr }}^{\prime}}{\mathrm{w}_{\text {corr }}}\right) \times 100
$$

where $\mathrm{W}_{\text {corr }}$ and $\mathrm{W}^{\prime}$ corr are AA3003 uninhibited and inhibited corrosion rate (in terms of $\mathrm{mg} \mathrm{cm}^{-2} \mathrm{day}^{-1}$ ), respectively. Fig. 3 summarized cysteine's calculated inhibition efficiency for $\mathrm{AA} 3003$ in a $2 \% \mathrm{NaCl}$ solution, at 2 and $11 \mathrm{pH}$ values. As it can be seen from this figure, the inhibition efficiency depended on $\mathrm{pH}$ values and concentrations of the tested amino acid, whereas cysteine showed the highest corrosion inhibitor properties in an alkaline medium. Further, this property decreases with an increased cysteine concentration for both tested $\mathrm{pH}$ values. This behavior can be attributed to the instability and dissolution of the formed molecular layer on a metallic surface, as reported by several authors [2930], which indicated the possible existence of an optimum concentration (at lower values) of this compound [28, 31].

On the other side, due to their highest precision [32], in the following parts of this study we have used two electrochemical methods to investigate and determine the inhibition efficiency of the tested amino acid in all $\mathrm{pH}$ values of the $2 \% \mathrm{NaCl}$ solution.

\section{Open-circuit potential (OCP) measurements}

OCP time dependence is commonly inferred as an overall indicator of a metallic material corrosion behavior [33]. AA3003's OCP was observed for 45 min from the electrode immersion in chloride solutions, in cysteine absence and presence. Fig. 4 represents OCP variation with the immersion time of the AA3003 electrode in naturally aerated $2 \% \mathrm{NaCl}$ solutions, at $\mathrm{pH}$ values varying from 2 to 11 , at $25^{\circ} \mathrm{C}$, in the presence of different cysteine concentrations. 


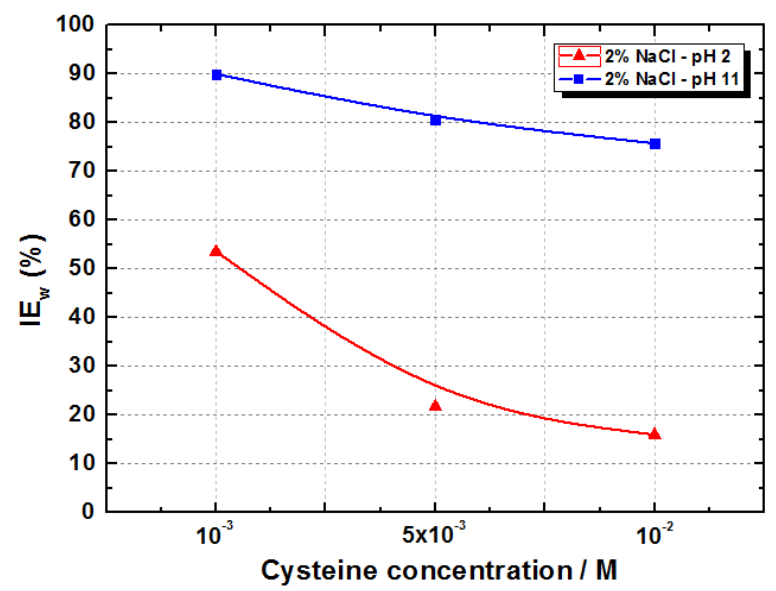

Figure 3. Inhibiting efficiency of cysteine in a $2 \% \mathrm{NaCl}$ ( 2 and $11 \mathrm{pH}$ values) solution, obtained by weight loss method at different concentrations for AA3003 (at $25 \pm 1{ }^{\circ} \mathrm{C}$ ).

In a $2 \% \mathrm{NaCl}$ solution at $\mathrm{pH} 2$, without cysteine (Fig. 4 (a)), it can be seen, during the first $30 \mathrm{~min}$ of AA3003 immersion, how the open circuit potential moves towards more negative values, and then keeps a constant value (steadypotential) around $-849 \mathrm{mV}$. This behavior has been attributed to the destruction and dissolution of the air formed pre-immersion $\mathrm{Al}_{2} \mathrm{O}_{3}$ layer, adjacent to the metal surface, and to outer porous modification [34]. However, in cysteine presence, the steady-potential shifted to more positive values with an increased concentration, in less time than that of the solution without cysteine. In general, this behavior could be attributed to a decrease in the metal activity, by cysteine molecules adsorption onto the metal surface [35-38].

In their turn, for the three last cases (i.e., 5, 8 and $11 \mathrm{pH}$ values), as shown in Fig. 4 (b), (c) and (d), AA3003 OCP in free cysteine solutions, as a whole, shifted from negative to more positive potentials (into noble directions), particularly, at 5 and $8 \mathrm{pH}$ values, which is often associated to a protective passive film formation at the AA3003 surface [32, 39]. As noted in Fig. 4 (c), with higher cysteine concentrations $\left(10^{-2} \mathrm{M}\right)$, in a solution at $\mathrm{pH} 8$, the potential was displaced to lower values. In its turn, the time to reach steady-potential value at $\mathrm{pH} 11$ was lesser than that for all other $\mathrm{pH}$ values of solutions without cysteine.

The same shapes of potential evolution have been found in cysteine presence. However, the steady-potential values of the AA3003 electrode depended on the solution's $\mathrm{pH}$, and on the additive concentration, as summarized in Fig. 5. Literature $[40,41]$ reveals that the shift in this value can be ascribed to the cysteine molecules interaction with the metal surface or with the oxide films. Therefore, we noted that $45 \mathrm{~min}$ of immersion time were enough to establish the AA3003 steady potential in all tested mediums.

\section{Potentiodynamic polarization}

Cysteine ability to act as a corrosion inhibitor for AA3003 was also investigated on the basis of Tafel polarization measurements. 

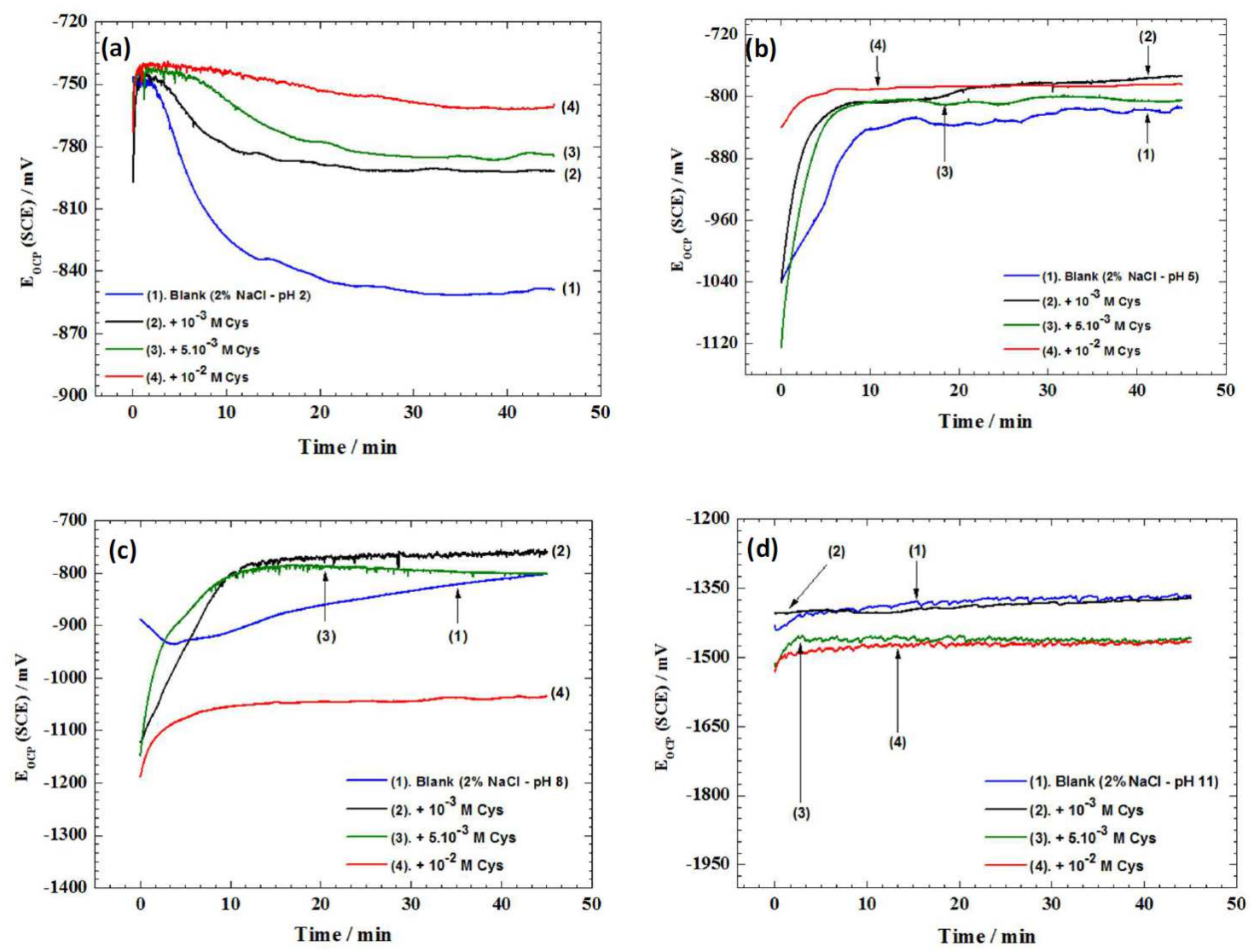

Figure 4. Evolution of the open-circuit potential (OCP) vs. AA3003 immersion time in $2 \% \mathrm{NaCl}$ solutions, at (a) 2, (b) 5, (c) 8 and (d) $11 \mathrm{pH}$ values, without and with various cysteine concentrations $\left(10^{-3}, 5 \times 10^{-3}\right.$ and $\left.10^{-2} \mathrm{M}\right)$, at $25 \pm 1{ }^{\circ} \mathrm{C}$.

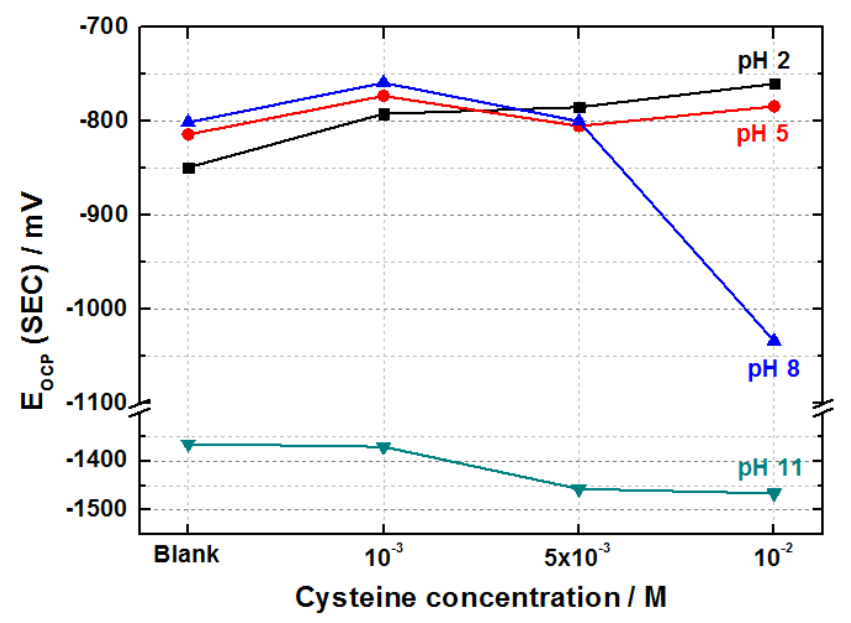

Figure 5. AA3003 steady open-circuit potential after 45 min of immersion in a $2 \%$ $\mathrm{NaCl}$ solution, with and without cysteine, at different $\mathrm{pH}$ values (at $25 \pm 1{ }^{\circ} \mathrm{C}$ ). 

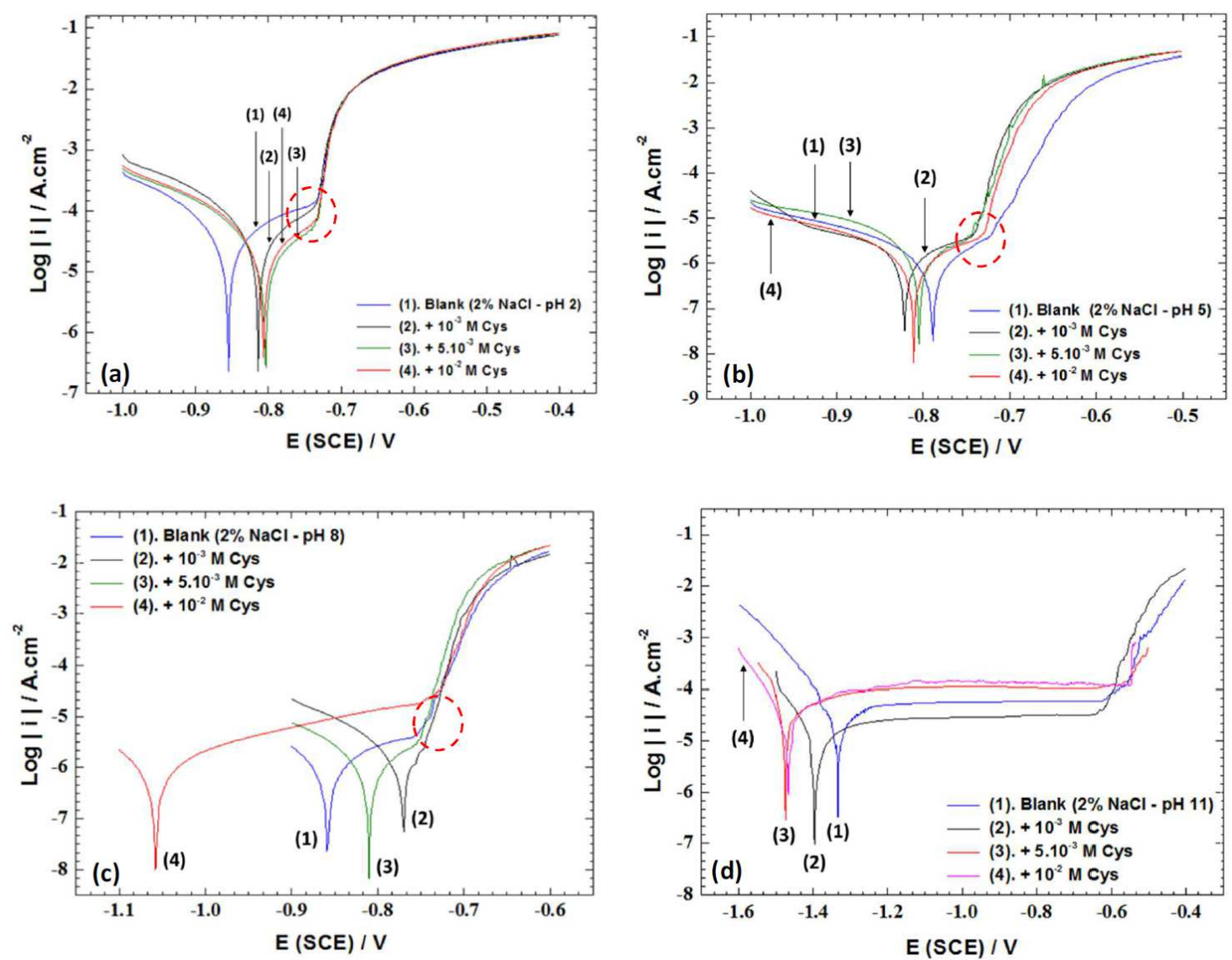

Figure 6. Potentiodynamic polarization curves recorded for AA3003 in $2 \% \mathrm{NaCl}$ solutions at (a) 2, (b) 5, (c) 8 and (d) $11 \mathrm{pH}$ values, without and with various cysteine concentrations $\left(10^{-3}, 5 \times 10^{-3}\right.$ and $\left.10^{-2} \mathrm{M}\right)$, at $25 \pm 1{ }^{\circ} \mathrm{C}$.

Fig. 6 represents the potentiodynamic polarization curves of AA3003 in a $2 \%$ $\mathrm{NaCl}$ solution, at different $\mathrm{pH}$ values, in the absence and presence of various cysteine concentrations. The electrochemical parameters, namely, corrosion current density $\left(i_{c o r r}\right)$, corrosion potential $\left(E_{c o r r}\right)$, and cathodic Tafel slope $\left(\beta_{c}\right)$, obtained from polarization curves, and the corresponding inhibition efficiency $\left(\mathrm{IE}_{\mathrm{i}}, \%\right)$ values, at different cysteine concentrations and $\mathrm{pH}$ values, are given in Table 1. As the anodic Tafel lines were invisible, the corrosion current density values, with and without the tested compound, were determined by manual extrapolation of the cathodic linear region, back to $E_{\text {corr }}[32,42]$. The inhibition efficiency was calculated by the following equation:

$$
\mathrm{IE}_{\mathrm{i}}(\%)=\left(1-\frac{\mathrm{i}_{\text {corr }}^{\prime}}{\mathrm{i}_{\text {corr }}}\right) \times 100
$$

where $\mathrm{i}_{\text {corr }}$ and $\mathrm{i}_{\text {corr }}$ are AA3003 corrosion current densities, in cysteine absence and presence, respectively.

From the polarization curves examination in Fig. 6, it is seen that AA3003 electrode polarization curves show similar behaviors at 2,5 and $8 \mathrm{pH}$ values of the $2 \% \mathrm{NaCl}$ blank solutions. In all these cases, the anodic current slightly increased from the corrosion potential $\left(\mathrm{E}_{\mathrm{corr}}\right)$ to a specific potential value (noted: $\mathrm{E}_{2}$ ), which depended on the $\mathrm{pH}$ value of the medium (indicated by the red circle 
in Fig. 6), and then sharply increased. In another research carried out in parallel with this study, we found that the plateau between $\mathrm{E}_{\mathrm{corr}}$ and $\mathrm{E}_{2}$ potential domain abruptly increased in hydrodynamic conditions, because the corrosion potential $\left(E_{\text {corr }}\right)$ shifted to more positives values, until it reached $E_{2}$ potential. However, for the cathodic part, the current has increased with decreasing potentials, and followed the Tafel's law [39, 42-43]. In contrast, in a $\% \mathrm{NaCl}$ solution at $\mathrm{pH} 11$ (Fig. $6(\mathrm{~d})$ ), the anodic part of the curve showed a constant current density, indicating a state of continuous passivity; then, the anodic current density remarkably increased with an increasing applied anodic potential (Table 1), which indicated the development of pitting processes, due to chloride ions [44]. As at previous $\mathrm{pH}$ values, at $\mathrm{pH} 11$ the cathodic part exhibited the same shape, as verified by Tafel relationship. Furthermore, AA3003 corrosion speed followed the same order as the one found by the weight loss method, which increased with the corrosion current density ( $\mathrm{i}_{\text {corr }}$ ), in this sequence: $\mathrm{pH} 2>\mathrm{pH} 11>>\mathrm{pH} 5>\mathrm{pH}$ 8 (see Fig. 2 (b)).

Table 1. Corrosion parameters and inhibition efficiency, $\mathrm{IE}_{\mathrm{i}}$, for $\mathrm{AA} 3003$ in a $2 \% \mathrm{NaCl}$ solution at different $\mathrm{pH}$ values, in the presence of different cysteine concentrations (at $\left.25 \pm 1{ }^{\circ} \mathrm{C}\right)$.

\begin{tabular}{|c|c|c|c|c|c|}
\hline \multicolumn{2}{|c|}{ Medium } & $\begin{array}{c}\mathbf{E}_{\text {corr }} \\
(\mathbf{m V})\end{array}$ & $\begin{array}{c}\mathbf{I}_{\text {corr }} \\
\left(\boldsymbol{\mu} \mathbf{~ c m}^{-2}\right)\end{array}$ & $\begin{array}{c}\boldsymbol{\beta}_{\mathbf{c}} \\
\left(\mathbf{m V} \mathbf{D e c}^{-1}\right)\end{array}$ & $\begin{array}{c}\text { IE1 } \\
(\%)\end{array}$ \\
\hline \multirow{4}{*}{$2 \% \mathrm{NaCl}-\mathrm{pH} 2$} & Blank & -854 & 52.5 & -155 & - \\
\cline { 2 - 6 } & $10^{-3} \mathrm{M}$ & -814 & 75.2 & -161 & -43 \\
\cline { 2 - 6 } & $5 \times 10^{-3} \mathrm{M}$ & -804 & 39.9 & -154 & 24 \\
\cline { 2 - 6 } & $10^{-2} \mathrm{M}$ & -806 & 43.5 & -172 & 17 \\
\hline \multirow{4}{*}{$2 \% \mathrm{NaCl}-\mathrm{pH} 5$} & $\mathrm{Blank}$ & -789 & 1.6 & -149 & - \\
\cline { 2 - 6 } & $10^{-3} \mathrm{M}$ & -822 & 1.1 & -101 & 31 \\
\cline { 2 - 6 } $2 \% \mathrm{NaCl}-\mathrm{pH} 8$ & $5 \times 10^{-3} \mathrm{M}$ & -805 & 1.4 & -84 & 13 \\
\cline { 2 - 6 } & $10^{-2} \mathrm{M}$ & -811 & 1.0 & -100 & 38 \\
\hline & $\mathrm{Blank}$ & -859 & 0.7 & -70 & - \\
\cline { 2 - 6 } & $10^{-3} \mathrm{M}$ & -762 & 1.2 & -76 & -71 \\
\cline { 2 - 6 } & $5 \times 10^{-3} \mathrm{M}$ & -810 & 0.9 & -73 & -29 \\
\cline { 2 - 6 } $2 \% \mathrm{NaCl}-\mathrm{pH}$ & $10^{-2} \mathrm{M}$ & -1058 & 0.5 & -69 & 29 \\
\cline { 2 - 6 } & $\mathrm{Blank}$ & -1337 & 39.9 & -104 & - \\
\cline { 2 - 6 } & $110^{-3} \mathrm{M}$ & -1395 & 8.1 & -80 & 80 \\
\cline { 2 - 6 } & $5 \times 10^{-3} \mathrm{M}$ & -1474 & 21.9 & -58 & 45 \\
\cline { 2 - 6 } & $10^{-2} \mathrm{M}$ & -1466 & 23.2 & -96 & 42 \\
\hline
\end{tabular}

Following Pourbaix (potential-pH) aluminum diagram, when the $\mathrm{pH}$ is within the range from 4 to 9 (5 and $8 \mathrm{pH}$ values, in our case), aluminum is oxidized to form a stable oxide film on the electrode $\left(\mathrm{Al}_{2} \mathrm{O}_{3}\right)$. The reactions in these conditions were characterized by equations (4) and (5) [1, 45]. It is well known that the main corrosion type of aluminum and its alloys, in $\mathrm{Cl}^{-}$ions presence, is the localized failure of the passive film, leading to the initiation, and then to the growth, of corrosion pits [44]. In a near neutral solution's $\mathrm{pH}$, the corrosion products formed on the AA generally consist of $\mathrm{Al}(\mathrm{OH})_{3}, \mathrm{Al}_{2} \mathrm{O}_{3}$ and $\mathrm{AlCl}_{3}$, as reported by B. Wang et al. [46], for 3A21 and 7A09 aluminum alloys.

$$
\text { Cathodic reaction (5 and } 8 \mathrm{pH} \text { values): } \frac{3}{2} \mathrm{O}_{2}+3 \mathrm{H}_{2} \mathrm{O}+6 \mathrm{e}^{-} \leftrightarrow 6 \mathrm{OH}^{-}
$$


Anodic reaction (5 and $8 \mathrm{pH}$ values): $2 \mathrm{Al}+6 \mathrm{OH}^{-} \leftrightarrow \mathrm{Al}_{2} \mathrm{O}_{3}+3 \mathrm{H}_{2} \mathrm{O}+6 \mathrm{e}^{-}$

On the other hand, below and above the 4-9 $\mathrm{pH}$ range (in our case, 2 and $11 \mathrm{pH}$ values), the oxide film $\left(\mathrm{Al}_{2} \mathrm{O}_{3}\right)$ solubility increases, and aluminum mostly exhibits an uniform attack [42, 47]. Equations (6) and (7) represent the cathodic and anodic reaction in acidic media, showing that aluminum dissolved to ion form $\left(\mathrm{Al}^{3+)}\right.$, with a clearance of hydrogen gas.

$$
\begin{aligned}
& \text { Cathodic reaction (pH 2): } 2 \mathrm{H}^{+}+2 \mathrm{e}^{-} \leftrightarrow \mathrm{H}_{2} \uparrow \\
& \text { Anodic reaction (pH 2): } \mathrm{Al} \leftrightarrow \mathrm{Al}^{3+}+3 \mathrm{e}^{-}
\end{aligned}
$$

However, in an alkaline solution, the previously formed aluminum oxide layer was dissolved by hydroxide ions, as indicated by reaction (8). Then, oxygen and/or water react with aluminum to form aluminum hydroxide, $\mathrm{Al}(\mathrm{OH})_{3}$, according to the reactions (4) and/or (9), and (10) [1, 48-51].

$$
\begin{aligned}
& \text { Dissolution reaction }\left(\mathrm{pH} \mathrm{11):} \mathrm{Al}_{2} \mathrm{O}_{3}+2 \mathrm{OH}^{-}+3 \mathrm{H}_{2} \mathrm{O} \rightarrow 2\left[\mathrm{Al}(\mathrm{OH})_{4}\right]^{-}\right. \\
& \text {Cathodic reaction ( } \mathrm{pH} \text { 11): } 2 \mathrm{H}_{2} \mathrm{O}+2 \mathrm{e}^{-} \leftrightarrow 2 \mathrm{OH}^{-}+\mathrm{H}_{2} \uparrow \\
& \text { Anodic reaction }(\mathrm{pH} 11): \mathrm{Al} \leftrightarrow \mathrm{Al}^{3+}+3 \mathrm{e}^{-}
\end{aligned}
$$

Examination of Fig. 6 and Table 1 clearly shows that the polarization shapes and slopes of cathodic Tafel lines $\left(\beta_{c}\right)$ of AA3003, with cysteine, were not substantially different from those without it. These results indicate that cysteine did not change AA3003 corrosion mechanism, at all investigated $\mathrm{pH}$ values of $2 \% \mathrm{NaCl}$ solutions [32-33], which was confirmed by another used electrochemical technique in this work (i.e., EIS). Likewise, we noted that cysteine addition shifted AA3003 corrosion potential towards positive values, at $\mathrm{pH} 2$, and towards negative values, at 5 and $11 \mathrm{pH}$ values of a $2 \% \mathrm{NaCl}$ solution. However, at $\mathrm{pH} \mathrm{8}$, there was not a definite tendency for of $\mathrm{E}_{\text {corr }}$ potential displacement, in cysteine presence. In this context, it is important to note that these potentials' trends were similar to those previously found in open circuit potential-time plots (see Fig. 4 and 5).

The inspection of the inhibition efficiency values given in Table 1 reveals that a weak concentration of cysteine, at 2 and $8 \mathrm{pH}$ values of a saline solution, accelerates AA3003 corrosion rate, compared to that of a blank solution. For the other concentrations and $\mathrm{pH}$ values, cysteine showed some ability as a corrosion inhibitor, in particular, in an alkaline ( $\mathrm{pH} 11) 2 \% \mathrm{NaCl}$ solution, which offered $80 \%$ inhibition efficiency at $10^{-3} \mathrm{M}$. However, as mentioned in Table 1 , IE has decreased with an increasing cysteine concentration. All those phenomena have been reported by several authors for cysteine and other amino acids compounds, for different metals in various media [26, 27, 52-54].

\section{Electrochemical impedance spectroscopy}

In order to obtain additional information on the electrochemical phenomena taking place on the interface metal-solution, without and with cysteine, ACimpedance measurements were carried out. At open circuit potential, impedance measurements have been performed. The potential values established during the 
stabilization in all tested media, and at which impedance spectra were recorded, are shown in Fig. 5. Fig. 7 summarizes the obtained spectra through AA3003 Nyquist representations, in different tested media.

Firstly, in an acidic (pH 2) $2 \% \mathrm{NaCl}$ solution, AA3003 Nyquist plots presented in Fig. 7 (a) are characterized by two time constants, namely: a depressed capacitive time constant at high frequency values, and an inductive time constant at low frequencies, either in cysteine absence and presence. Similar behavior has been found by $\mathrm{A}$. Yurt et al. [42], for aluminum in a $0.1 \mathrm{M} \mathrm{HCl}$ solution. In literature, there is no common agreement about the origin of these time constants in impedance spectra $[35,55]$. In these spectra, at high frequencies, the depressed capacitive loop attributed to the corrosion charge transfer process, concerning the semicircle's depressive character, was mostly assigned to the inhomogeneous metal surface [48]. The second time constant at low frequencies (inductive loop) is often related to the species' surface relaxation, or to the adsorption of the intermediate products of the corrosion reaction onto the surface (involving cysteine addition), as well as of the reactive products [35, 42, 56-59].
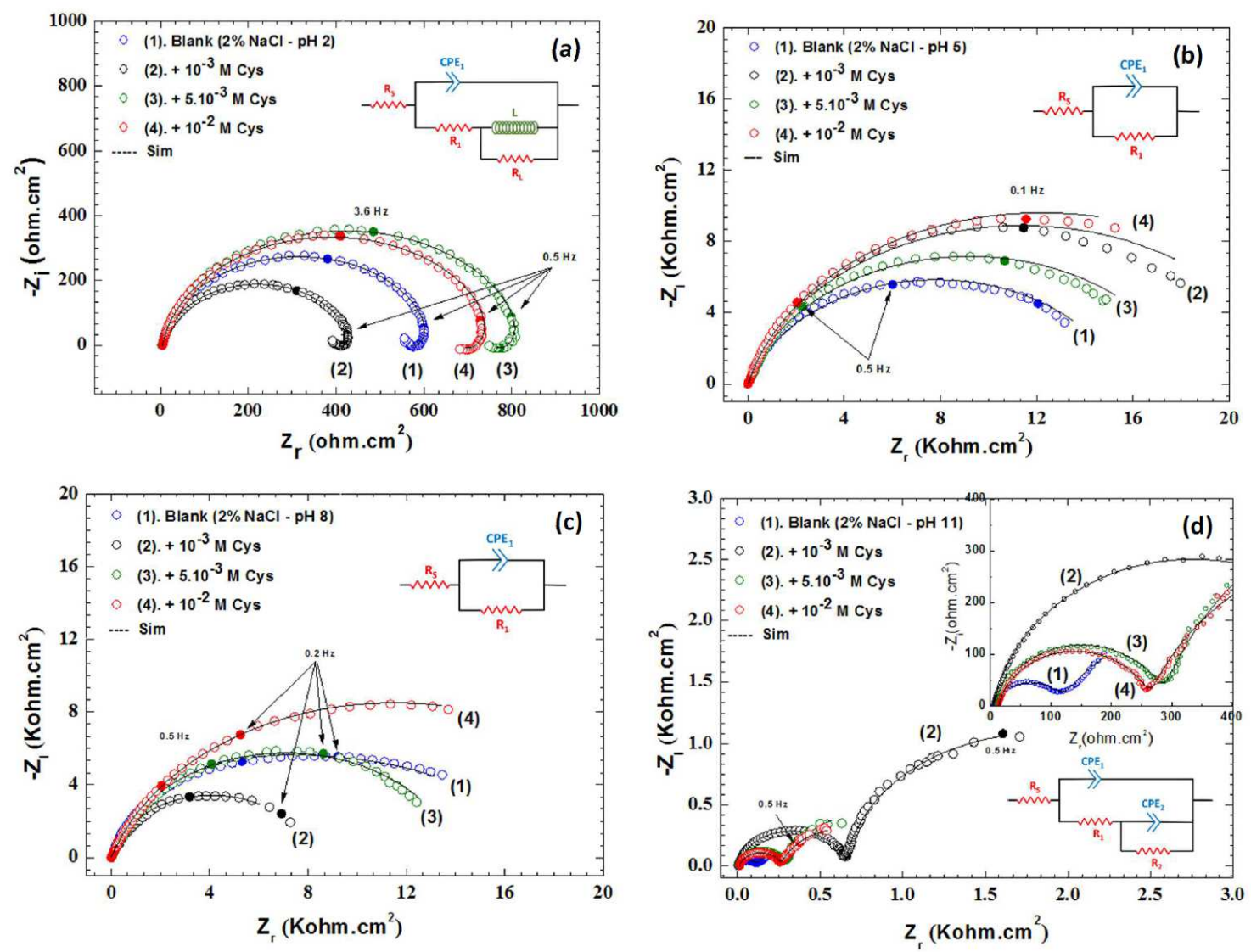

Figure 7. Nyquist plots of electrochemical impedance spectra for AA3003 in $2 \% \mathrm{NaCl}$ solutions at (a) 2, (b) 5, (c) 8 and (d) $11 \mathrm{pH}$ values, without and with various cysteine concentrations $\left(10^{-3}, 5 \times 10^{-3}\right.$ and $\left.10^{-2} \mathrm{M}\right)$, at $25 \pm 1{ }^{\circ} \mathrm{C}$. The used equivalent circuits' models to fit EIS data are incorporated in each spectrum.

In near neutral ( 5 and $8 \mathrm{pH}$ values) $2 \% \mathrm{NaCl}$ solutions, the all complex-plan impedances for AA3003, without and with cysteine, exhibited (in Fig. 7 (b) and (c)) an alone depressed (due to the inhomogeneous metal surface) semi-circle, 
showing that cysteine did not change the corrosion mechanism of aluminum alloy at 5 and $8 \mathrm{pH}$ values, which is mainly charge transfer controlled $[9,48]$. In other words, its diameter is a function of $\mathrm{pH}$ values and cysteine concentration.

The last tested medium was an alkaline ( $\mathrm{pH} 11$ ) $2 \% \mathrm{NaCl}$ solution (Fig. 7 (d)). In cysteine absence and presence, at various concentrations, the impedance diagrams show two depressed capacitive loops, one in high frequencies and another in low frequencies. The first loop could be assigned to the double layer and charge transfer characteristics. The second loop, in lower frequencies, can be connected to the corrosion products film formation on the AA3003 surface [55]. The depressive character was mainly assigned to the inhomogeneous metal surface [48].

The equivalent circuits' models used to fit AA3003 experimental data depended on the $\mathrm{pH}$ value of the medium. These electric equivalent circuits (integrated in Fig. 7) involve the following elements: $R_{S}, R_{c t-1}, R_{c t-2}, R_{L}, L,(C P E)_{1}$ and $(C P E)_{2}$. In these circuits, $\mathrm{R}$ represents resistor elements, ct designs the charge transfer, $\mathrm{L}$ represents the inductance element that is related to the inductive time constant at low frequencies in the EIS spectrum, and CPE are the constant phase elements, of which impedance is given by:

$$
\mathrm{Z}_{\mathrm{CPE}}=\mathrm{Q}^{-1}(\mathrm{j} \omega)^{-\mathbf{n}}
$$

where $\mathrm{j}$ is an imaginary number, $\omega$ is the angular frequency in $\operatorname{rad~s}^{-1}$ and $\mathrm{n}$ is the impedance depressed feature [35]. This impedance term is employed to describe the distribution of relaxation times, as a result of the inhomogeneity present at the solid/liquid interface on a microscopic level [55]. The ${ }_{1}$ and ${ }_{2}$ for both $\mathrm{R}_{\mathrm{ct}}$ (i.e., $\mathrm{R}_{\mathrm{ct}-1}$ and $\mathrm{R}_{\mathrm{ct}-2}$ ) and $\mathrm{CPE}$ (i.e., $(\mathrm{CPE})_{1}$ and $\left.(\mathrm{CPE})_{2}\right)$ refer to the first and second depressed capacitive loop, respectively. The aim of the fitting procedure was to find those parameter values that best describe the data; in other words, the fitting model must be consistent with the experimental data $[35,60]$. As show in Fig. 7, a good fit with these circuit models, regarding our experimental impedance data, was obtained.

The parameters determined from Nyquist plots, by the regression calculation to equivalent circuits' models, and the inhibition efficiency $\left(\mathrm{IE}_{\mathrm{z}}, \%\right)$, are given in Table 2. The inhibition efficiency proportion at different cysteine concentrations, for each tested medium, was calculated from charge transfer values, according to the following equation:

$$
\mathrm{IE}_{\mathrm{z}}(\%)=\left(1-\frac{\mathrm{R}_{\mathrm{ct}}^{0}}{\mathrm{R}_{\mathrm{ct}}}\right) \times 100
$$

where $R_{c t}^{0}$ and $R_{c t}$ are AA3003 total charge transfer resistances, without and with cysteine in the tested medium, respectively. In the cases of acidic $(\mathrm{pH} 2)$ and near neutral ( 5 and $8 \mathrm{pH}$ values) $2 \% \mathrm{NaCl}$ solutions, the latest grandeur was Rct-1 value. However, in alkaline media (i.e., $\mathrm{pH} 11$ ), it was the sum of the two resistances (Rct-1 and Rct-2) that was associated to the first and second loop, respectively (see Fig. 7 (d)) [41-42].

As it is well known, the charge transfer resistance, $R_{c t}$, is inversely proportional to the corrosion rate [35]. Consequently, AA3003 dissolution rate decreases in the following order: $\mathrm{pH} 2>\mathrm{pH} 11>>$ pH $5>$ pH 8 (see Fig. 2 (b)). Furthermore, 
the data of Table 2 reveal that $R_{t c}$ and CPE values depend on cysteine concentration and $\mathrm{pH}$ value of the medium. Looking at the calculated inhibition efficiency, cysteine in an alkaline $(\mathrm{pH} \mathrm{11)} 2 \% \mathrm{NaCl}$ solution showed the highest inhibition performance $(81 \%)$ at $10^{-3} \mathrm{M}$, compared to the other media; then, it declined with its concentration, at the same $\mathrm{pH}$ value (i.e., $\mathrm{pH} 11$ ). With lower concentrations, at 2 and $8 \mathrm{pH}$ values, cysteine has accelerated (catalyzed) the corrosion processes, although it has presented some ability to inhibit the corrosion at higher concentrations. Generally, at $\mathrm{pH} \mathrm{5,} \mathrm{this} \mathrm{amino} \mathrm{acid} \mathrm{has} \mathrm{not} \mathrm{a}$ defined trend concerning the inhibition efficiency. Concluding this part, these results (EIS measurements) are comparable, and run parallel to those recorded by the potentiodynamic polarization method. Furthermore, those results confirmed the complex effect of cysteine on AA3003 corrosion in these conditions.

Table 2. Fitted values of the parameters associated to the impedance diagrams of Fig. 7.

\begin{tabular}{|c|c|c|c|c|c|c|c|c|c|c|}
\hline \multicolumn{2}{|c|}{ Medium } & $\begin{array}{c}R_{\mathrm{S}} \\
\left(\Omega \mathrm{cm}^{2}\right)\end{array}$ & $\begin{array}{c}\mathbf{R}_{\mathrm{ct}-1} \\
\left(\Omega \mathrm{cm}^{2}\right)\end{array}$ & $\begin{array}{c}\mathbf{R}_{\mathrm{ct}-2} \\
\left(\Omega \mathbf{c m}^{2}\right)\end{array}$ & $\begin{array}{c}\mathbf{R}_{\mathrm{ct}} \\
\left(\Omega \mathrm{cm}^{2}\right)\end{array}$ & $\begin{array}{c}\mathrm{L} \\
\left(\mathrm{H} \mathrm{cm}^{2}\right)\end{array}$ & $\begin{array}{c}\mathbf{R}_{\mathrm{L}} \\
\left(\Omega \mathbf{c m}^{2}\right)\end{array}$ & $\begin{array}{c}\mathrm{CPE}_{1} / \mathbf{n}_{1} \\
\left(\mathrm{~S} \mathrm{~s}^{\mathrm{n}} \mathbf{c m}^{-2}\right)\end{array}$ & $\begin{array}{c}\mathrm{CPE}_{2} / \mathbf{n}_{2} \\
\left(\mathrm{~S} \mathrm{~s}^{\mathrm{n}} \mathbf{c m}^{-2}\right)\end{array}$ & $\begin{array}{l}I E_{z} \\
(\%)\end{array}$ \\
\hline \multirow{4}{*}{$\begin{array}{c}2 \% \\
\mathrm{NaCl} \\
\mathrm{pH} 2\end{array}$} & Blank & 4.42 & 565.5 & - & 565.5 & 32.38 & 59.05 & 7.432 E-5 / 0.9175 & - & - \\
\hline & $10^{-3} \mathrm{M}$ & 4.20 & 402.7 & - & 402.7 & 22.66 & 32.95 & 8.534 E-5 / 0.9093 & - & -40 \\
\hline & $\begin{array}{l}5 \times 10^{-3} \\
M\end{array}$ & 4.00 & 757.9 & - & 757.9 & 62.68 & 79.06 & 6.072 E-5 / 0.8924 & - & 25 \\
\hline & $10^{-2} \mathrm{M}$ & 4.73 & 683.8 & - & 683.8 & 55.19 & 88.25 & 7.105 E-5 / 0.9089 & - & 17 \\
\hline \multirow{4}{*}{$\begin{array}{c}2 \% \\
\mathrm{NaCl} \\
\text { pH } 5\end{array}$} & Blank & 4.10 & 14130.0 & - & 14130.0 & - & - & $0.0363 / 0.819$ & - & - \\
\hline & $10^{-3} \mathrm{M}$ & 4.48 & 24450.0 & - & 24450.0 & - & - & $0.7617 / 0.8093$ & - & 42 \\
\hline & $\begin{array}{l}5 \times 10^{-3} \\
M\end{array}$ & 4.18 & 17360.0 & - & 17360.0 & - & - & $0.0775 / 0.797$ & - & 19 \\
\hline & $10^{-2} \mathrm{M}$ & 4.17 & 22470.0 & - & 22470.0 & - & - & $0.0775 / 0.981$ & - & 37 \\
\hline \multirow{4}{*}{$\begin{array}{c}2 \% \\
\mathrm{NaCl} \\
\mathrm{pH} 8\end{array}$} & Blank & 4.90 & 16650.0 & - & 16650.0 & - & - & $0.0433 / 0.818$ & - & - \\
\hline & $10^{-3} \mathrm{M}$ & 4.80 & 9580.0 & - & 9580.0 & - & - & $0.0786 / 0.790$ & - & -74 \\
\hline & $\begin{array}{l}5 \times 10^{-3} \\
\mathrm{M}\end{array}$ & 4.75 & 13550.0 & - & 13550.0 & - & - & $0.0506 / 0.807$ & - & -23 \\
\hline & $10^{-2} \mathrm{M}$ & 4.37 & 21840.0 & - & 21840.0 & - & - & $0.0808 / 0.815$ & - & 24 \\
\hline \multirow{4}{*}{$\begin{array}{c}2 \% \\
\mathrm{NaCl} \\
\mathrm{pH} \\
11\end{array}$} & Blank & 4.88 & 118.0 & 471.9 & 589.9 & - & - & 9.795 E-5 / 0.8196 & $\begin{array}{c}0.00712 / \\
0.7471\end{array}$ & - \\
\hline & $10^{-3} \mathrm{M}$ & 6.98 & 657.9 & 2382 & 3039.9 & - & - & 8.819 E-7 / 0.9064 & $\begin{array}{c}0.00018 / \\
0.9406\end{array}$ & 81 \\
\hline & $\begin{array}{l}5 \times 10^{-3} \\
M\end{array}$ & 4.37 & 279.1 & 1086 & 1365.1 & - & - & 4.168 E-6 / 0.897 & $\begin{array}{c}0.00630 / \\
0.8566\end{array}$ & 57 \\
\hline & $10^{-2} \mathrm{M}$ & 4.36 & 251.3 & 797.9 & 1049.2 & - & - & 2.045 E-5 / 0.8875 & $\begin{array}{c}0.00470 / \\
0.8311\end{array}$ & 44 \\
\hline
\end{tabular}

\section{Weight loss method vs. electrochemical methods}

The results of gravimetric measurements indicate that cysteine, at 2 and $11 \mathrm{pH}$ values, with all concentrations, presents a corrosion inhibiting property. However, the electrochemical measurements (PP and EIS) exclude $10^{-3} \mathrm{M}$ concentration at $\mathrm{pH}$ 2, which has accelerated the corrosion processes (Fig. 8). This can be related to the immersion time effect ( $45 \mathrm{~min}$ for the electrochemical method, and 24 hours for the weight loss study), which can affect the stability of the used compound. A similar trend has been reported in the literature for other systems [61-62]. In this context, it is well known that, in an aerated solution, cysteine (RSH) is oxidized by the dissolved oxygen, forming a dimer with a disulfide bridge, called cystine (RSSR) [18, 63-65]. The half reaction equation is given by equation (13). In other words, the concentration of the formed dimer (RSSR), at 24 hours (weight loss method), was higher than at $45 \mathrm{~min}$ 
(electrochemical method). Furthermore, in several studies [66-68], the RSSR dimer has showed considerable ability to inhibit corrosion. Consequently, if there is a cysteine accelerator effect at lower concentrations (as at $\mathrm{pH} 2$ ), this can be related to the metal dissolution by the formation of soluble complexes between the metal ion and cysteine, via the sulfhydryl group (-SH) [69].

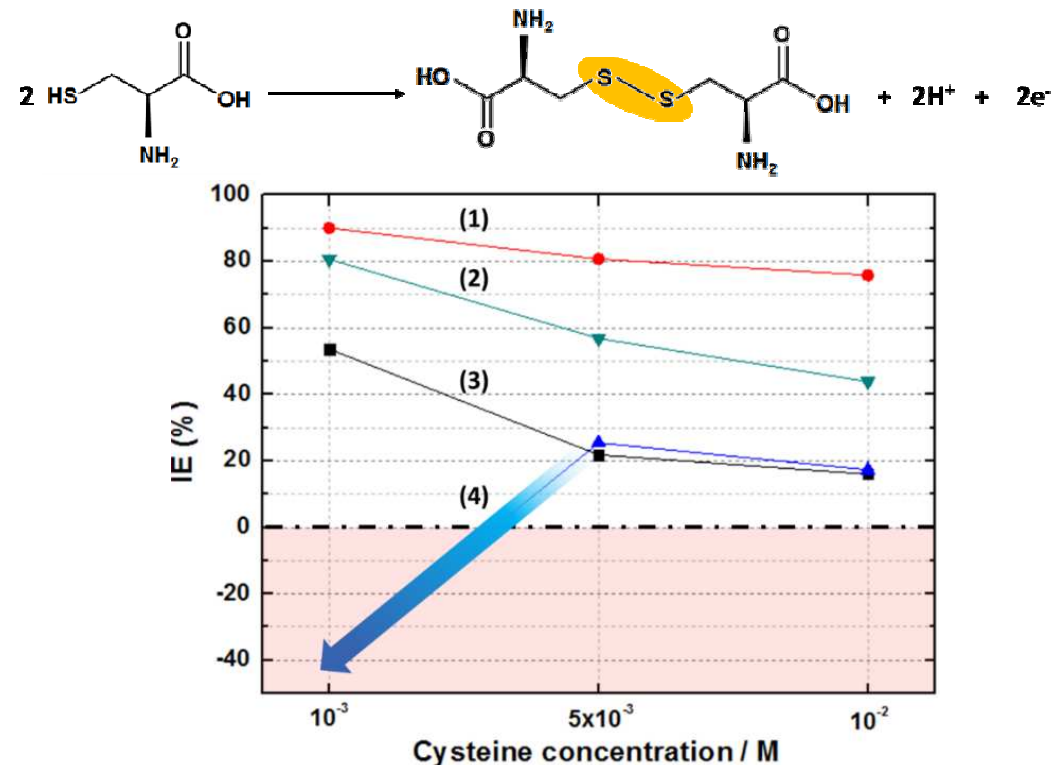

Figure 8. Obtained inhibition efficiencies (IE, \%) of cysteine at different concentrations $\left(10^{-3}, 5 \times 10^{-3}\right.$ and $\left.10^{-2} \mathrm{M}\right)$ by weight loss $(\mathbf{1}, \mathbf{3})$ and electrochemical (EIS) methods $(2$, $4)$, at $11(\mathbf{1}, \mathbf{2})$ and $2(3,4) \mathrm{pH}$ values of a $2 \% \mathrm{NaCl}$ solution.

\section{Surface morphology}

In order to get information about AA3003 surface morphological state, and about the effect of cysteine on this feature, SEM analysis was performed. Cysteine concentration of $5 \times 10^{-3} \mathrm{M}$ was chosen, due to its reasonable inhibition efficiency, both in acidic and alkaline media. Fig. 9 presents AA3003 typical surface morphology, before and after its immersion (for 24 hours) in a $2 \% \mathrm{NaCl}$ solution, without and with cysteine, at 2 and $11 \mathrm{pH}$ values. In the first stage, compared to AA3003 presence (Fig. 9 (a)), the surface morphology in blank solutions (Fig. 9 (b) and (c)) was strongly corroded by the aggressive solution, and it became scratched and porous, both at 2 and $11 \mathrm{pH}$ values of $2 \% \mathrm{NaCl}$ solutions. These observations perfectly correlate to the highest corrosion rate of the tested blank solutions, as proved by previous techniques (Fig. 2 (b)). In the second stage, cysteine (at $5 \times 10^{-3} \mathrm{M}$ ) beneficially affected AA3003 surface morphology, as the specimens (Fig. 9 (d) and (e)) were better protected than in solutions without cysteine (Fig. 9 (b) and (c)). However, some heterogeneities remain on AA3003 surfaces, in cysteine presence. Such observations agree with the obtained inhibition efficiency at $5 \times 10^{-3} \mathrm{M}$, namely, $25 \%$ and $57 \%$, at 2 and $11 \mathrm{pH}$ values, respectively. 


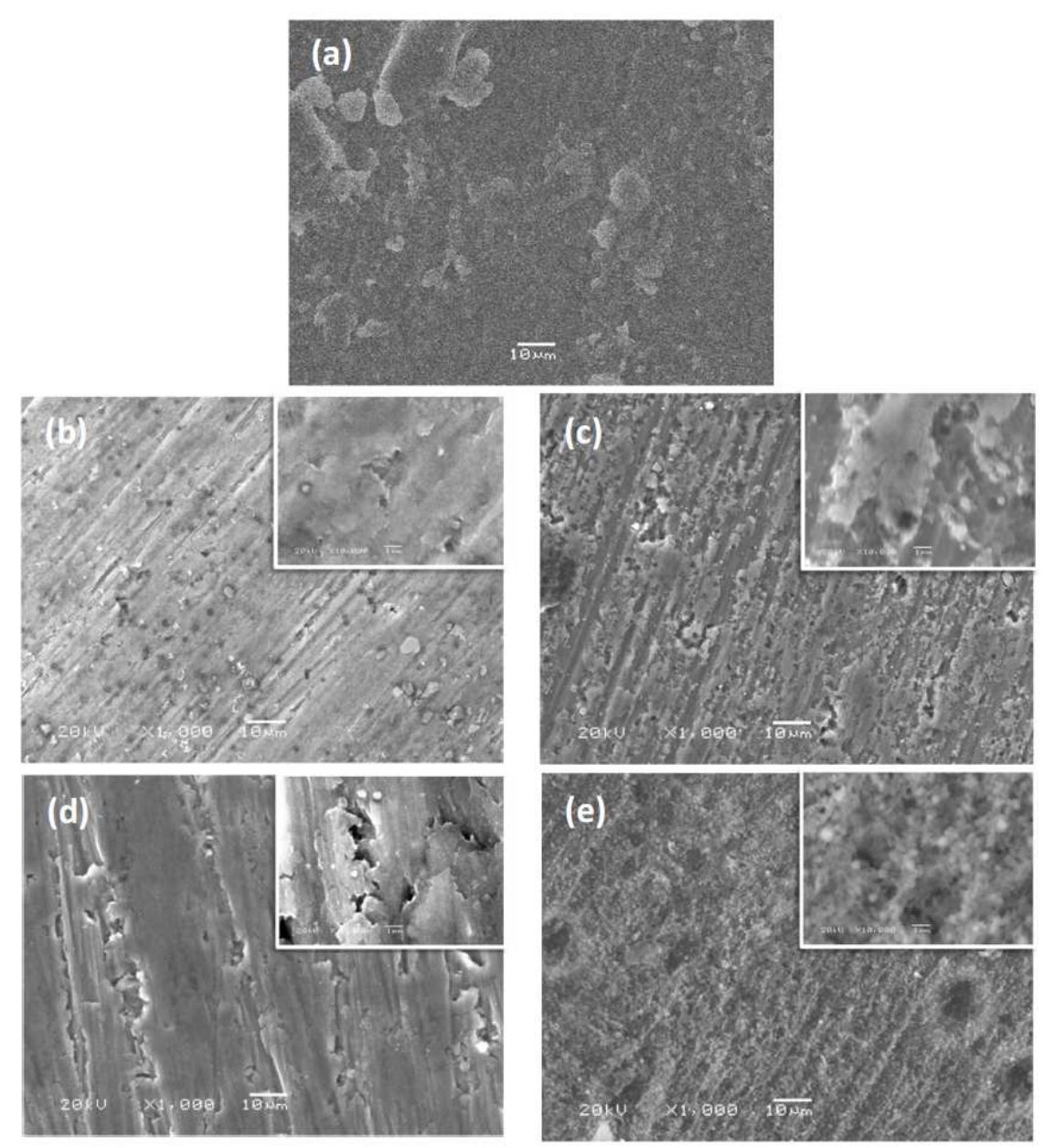

Figure 9. AA3003 SEM images (X1000 and X2000) before (a) and after immersion in a $2 \% \mathrm{NaCl}$ solution without and with cysteine $\left(5 \times 10^{-3} \mathrm{M}\right)$, for 24 hours, at $2(\mathbf{b}, \mathbf{c})$ and $11(\mathbf{d}, \mathbf{e}) \mathrm{pH}$ values.

\section{Mechanism of action}

Usually, the inhibition efficiency increases with the inhibitor concentration [1217, 32]. However, in our case, no linear trend was found, and IE strongly depended on cysteine concentration and on the saline solution's pH (see Fig. 10). For this purpose, the solution's $\mathrm{pH}$ is an important element to explain obtained results, because it may influence amino acids molecules (protonated, deprotonated or zwitterion forms), the metallic surface and the corrosion mechanism [25]. Depending on the solution's $\mathrm{pH}$, cysteine is presented in different forms (Fig. 1) [19]. Fig. 11 (a) shows the cysteine solution composition (by molar ration: $\alpha$ ) as a function of $\mathrm{pH}$. This diagram was produced by using CurTiPot 4.1.1. Microsoft Excel Macro file, programmed by Ivano G.R. Gutz [70]. 


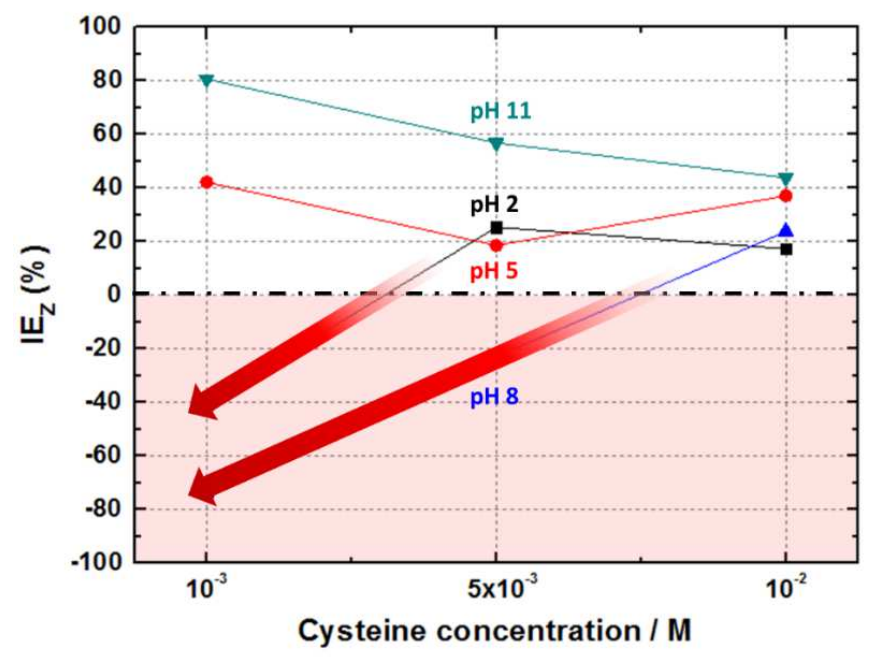

Figure 10. Cysteine inhibition efficiency (obtained from EIS technique) at $10^{-3}, 5 \times 10^{-3}$ and $10^{-2} \mathrm{M}$, as a function of the $2 \% \mathrm{NaCl}$ solution's $\mathrm{pH}$.
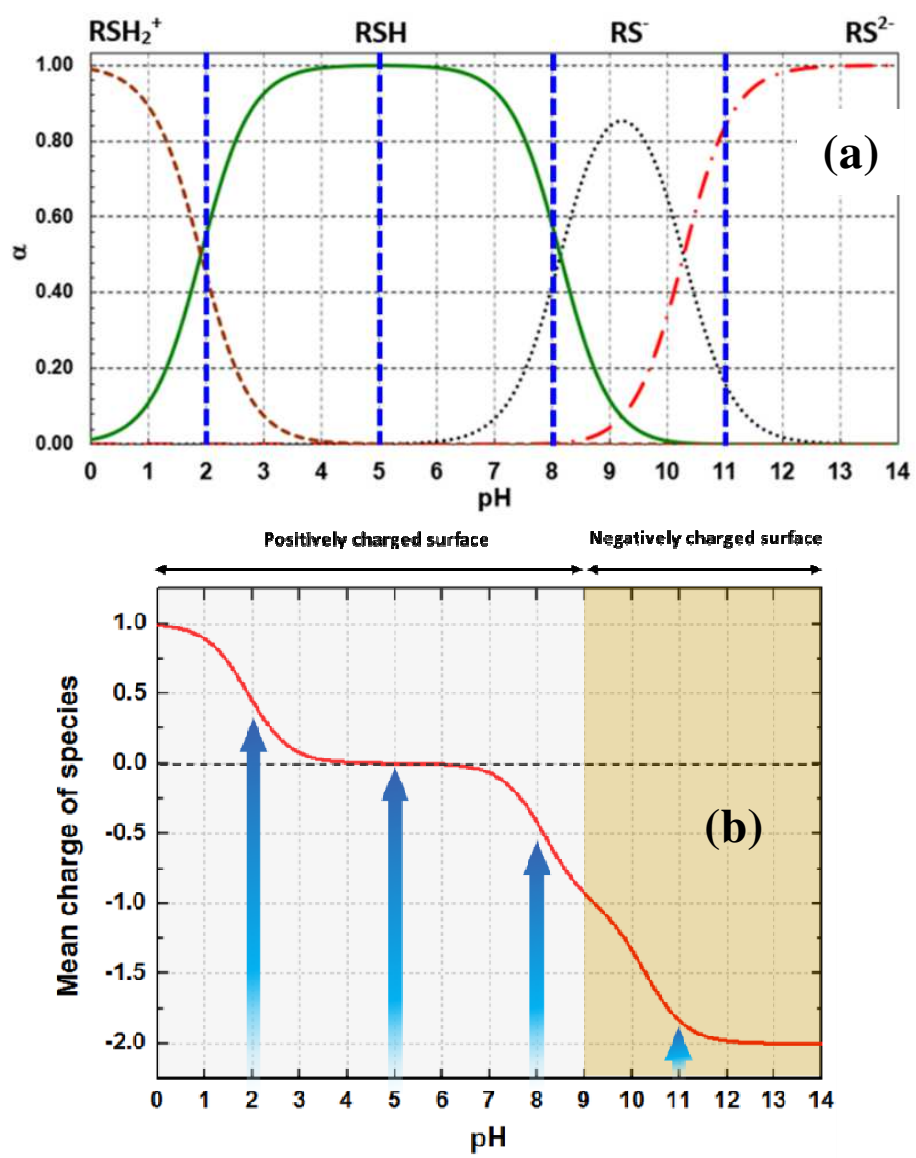

Figure 11. (a) Composition of cysteine solution as a function of $\mathrm{pH}$ value. (b) Mean charge of cysteine species as a function of $\mathrm{pH}$. The gray and brown areas represent the range of $\mathrm{pH}$ at which the aluminum alloy surface was positively $(\mathrm{pH}<9)$ and negatively $(\mathrm{pH}>9)$ charged, respectively.

As it can be seen, at 5 and $11 \mathrm{pH}$ values, the solution was mainly constituted by two forms of cysteine: zwitterions (I) and deprotonated (II) forms, respectively. However, at 2 and $8 \mathrm{pH}$ values, both solutions contained a mixture of two cysteine forms, namely, 55\% protonated cysteine with $45 \%$ of zwitterions, and 
$58 \%$ of zwitterion with $42 \%$ deprotonated cysteine, respectively. The zwitterion form was dominant, at the $\mathrm{pH}$ range from 1.9 to 8.2. Below or above these $\mathrm{pH}$ values, the molecules are cationic or anionic, respectively. The $\mathrm{pH}$ effect on the aluminum alloy surface state is visible in its electric charge and corrosion products. So, below pH 9, it is positively charged, and above this value, it is negatively charged [32]. The chemical nature of AA3003 surface (corrosion products) was discussed in the previous part about the potentiodynamic polarization study. As reported in some works [40, 71], cysteine adsorption mode (chemisorption or physisorption) was found to depend on the $\mathrm{pH}$ value of the medium. Fig. 11 (b) represents the mean charge of cysteine, as a function of $\mathrm{pH}$, with a superposed charge of the metal surface [70].

As it can be seen in Fig. 11 (b), there is not a relationship between the mean charge of cysteine species and that of the metal surface, at 2, 5 and $11 \mathrm{pH}$ values. This indicates that the direct physisorption process cannot satisfactorily explain cysteine behavior in these cases, because this process was characterized by an electrostatic interaction (dipole interaction) between the charged molecules and the charged metal surface [72]. A possible reason for these results is the chemisorption interaction of the species with the surface. However, at $\mathrm{pH} 11$, IE decreases with an increasing cysteine concentration. Furthermore, at $\mathrm{pH} 5$, no IE trend was noted with cysteine concentration. The same observation was noted at 2 and $8 \mathrm{pH}$ values, with high cysteine concentrations. All these notes reflect the instability of the formed adsorbed inhibitor film and, consequently, its dissolution [9], which can be due to the weak chemisorption of cysteine molecules onto the metal surface [69]. At 2 and $8 \mathrm{pH}$ values, with low cysteine concentrations, this amino acid acted as a corrosion accelerator (with negative IE values (\%)) for AA3003 in $2 \% \mathrm{NaCl}$. Commonly, this effect was explained by a competition between strong cysteine complexation with metallic ions and its weak chemisorption onto the metal surface [28, 29, 52, 69]. In the whole (see Fig. 11 (b)), the inhibition effectiveness at $\mathrm{pH} 5$ was greater than that at 2 and 8 $\mathrm{pH}$ values, which can be attributed to the cysteine solution composition. From Fig. 11 (a), at $\mathrm{pH} \mathrm{5,} \mathrm{the} \mathrm{solution} \mathrm{was} \mathrm{composed} \mathrm{from} \mathrm{Zwitterion} \mathrm{(RSH).}$ However, in addition to the RSH form, at 2 and $8 \mathrm{pH}$ values, the solution also contained other forms: deprotonated I $\left(\mathrm{RSH}^{2+}\right)$ and deprotonated II ( $\left.\mathrm{RS}^{-}\right)$forms, respectively. In addition to its proportion reduction, compared to at $\mathrm{pH} \mathrm{5,} \mathrm{it} \mathrm{is}$ possible that the RSH form could have interfered with the other cysteine forms (at 5 and $8 \mathrm{pH}$ values) and, hence, reduce the RSH concentration adsorbed onto the surface. This interference can be favored by the soft chemisorbed RSH form. The same behavior was noted at $\mathrm{pH} 11$, of which the main form was $\mathrm{RS}^{2-}$ anion. As a finding, corrosion inhibition by cysteine exhibited high complexity. In order to understand better this corrosion inhibition or acceleration effect on AA3003 in a saline solution, a second work will discuss it via quantum chemical calculations and molecular Monte Carlo simulations. 


\section{Conclusions}

Cysteine ability to inhibit 3003 aluminum alloy corrosion in a $2 \% \mathrm{NaCl}$ solution, at different $\mathrm{pH}$ conditions, was examined by weight loss and electrochemical methods. Firstly, it was found that AA3003 corrosion rate and mechanism depended on $\mathrm{pH}$ values. Then, a strong dependence was showed for cysteine inhibition efficiency on its concentrations, as well as the saline solution's $\mathrm{pH}$. In this context, the investigated amino acid (i.e. cysteine) exhibited a better corrosion inhibitory effect in an alkaline medium, regarding all tested $\mathrm{pH}$ values. However, it acted as a corrosion accelerator in lower concentrations, at 2 and 8 $\mathrm{pH}$ values. Furthermore, as a whole, no increasing linear behavior of the inhibition efficiency with the concentration was observed. These results allowed the prediction that, in the-AA3003 case in a $2 \% \mathrm{NaCl}$ solution, cysteine (or its dimerized form, cystine) would be adsorbed onto the metal surface through a weak chemisorption process. Finally, following our results and the literature findings, the use of cysteine as a metal corrosion inhibitor must be accompanied by some precautions to avoid its corrosion catalytic effect.

\section{Acknowledgements}

B. EL IBRAHIMI expresses his appreciation for the support from Morocco CNRST, through the excellence scholarship of the searching program (2014 Edition).

The laboratory of Engineering and Materials Science (LISM), University of Reims Champagne Ardenne (France), is gratefully acknowledged for surface morphology analysis.

\section{References}

1. Vargel C. Corrosion of Aluminium. $1^{\text {st }}$ ed. Elsevier; 2004.

2. Lumley R. Fundamentals of aluminium metallurgy: Production, processing and applications. 1st ed. UK:Woodhead Publishing Ltd; 2011.

3. Wang D, Gao L, Zhang D, et al. Mater Chem Phys. 2016;169:142.

4. Sastri VS. Green Corrosion Inhibitors: Theory and Practice. 1st ed. John Wiley \& Sons Ltd; 2011.

5. Raja PB, Sethuraman MG. Mater Lett. 2008;62:113-116.

6. Rani BEA, Basu BBJ. Int J Corrosion. 2012;2012:15.

7. Gece G. Corrosion Sci. 2011;53:3873.

8. Kiani MA, Mousavi MF, Ghasemi S, et al. Corrosion Sci. 2008;50:1035.

9. Zhang DQ, Xie B, Gao LX, et al. J Appl Electrochem. 2011;41:491.

10. Fu JJ, Li SN, Cao LH, et al. J Mater Sci. 2010;45:979.

11. El Ibrahimi B, Jmiai A, Bazzi L, et al. Arab J Chem. 2017. In press. https://doi.org/10.1016/j.arabjc.2017.07.013.

12. Fekry AM, Tammam RH. Int J Electrochem Sci. 2012;7:12254.

13. Rajappa SK, Venkatesha TV. Tur. . Chem. 2003;27:189.

14. El-Sherif RM, Badawy WA. Int J Electrochem Sci. 2011;6:6469.

15. Salghi R, Hammouti B, Kertit S, et al. Bull Electrochem. 1997;13:399. 
16. Zerfaoui M, Oudda H, Hammouti B, et al. Prog Org Coat. 2004;51:134.

17. Matos JB, Pereira LP, Agostinho SML,et al. J Electroanal Chem. 2004;570:91.

18. Silva AB, Agostinho SML, Barcia OE, et al. Corrosion Sci. 20016;48:3668.

19. Kilberg MS, Häussinger D. Mammalian Amino Acid Transport. Springer Science \& Business Media; 1992.

20. Milošev I, Pavlinac J, Hodošček M, et al. J Serb Chem Soc. 2013;78:2069.

21. Kabanda MM, Obot IB, Ebenso EE. Int J Electrochem Sci. 2013;8:10839.

22. Zarrouk A, Zarrok H, Salghi R, et al. Int J Electrochem Sci. 2012;7:6353.

23. Eddy NO. J Adv Res. 2011;2:35.

24. Zhang DQ, Gao LX, Zhou GD. J Appl Electrochem. 2005;35:1081.

25. Varvara S, Rotaru I, Popa M, et al. Rev Roum Chim. 2011;56:793.

26. Kalota DJ, Silverman DC. Corrosion. 1994;50:138.

27. Helal NH, El-Rabiee MM, El-Hafer GMA, et al. J Alloys Compd. 2008;456:372.

28. Ismail KM. Electrochim Acta. 2007;52:7811.

29. Shkirskiy V, Keil P, Hintze-Bruening H, et al. Corrosion Sci. 2015;100:101.

30. Aramaki K. Corrosion Sci. 2001;43:2201.

31. Shen S, Guo X-Y, Song P, et al. Appl Surf Sci. 2013;276:167.

32. Amin MA. Corrosion Sci. 2010;52:3243.

33. Zaid B, Maddache N, Saidi D, et al. J Alloys Compd. 2015;629:188.

34. Haleem SMAE, Wanees SAE, Aal EEAE, et al. Corrosion Sci. 2013;68:1.

35. Khaled K. Corrosion Sci. 2010;52:2905.

36. Zhang Q, Gao Z, Xu F, et al. Colloids Surf. 2011;380:191.

37. Şafak S, Duran B, Yurt A, et al. Corrosion Sci. 2012;54:251.

38. Yurt A, Aykın Ö. Corrosion Sci. 2011;53:3725.

39. Zaid B, Saidi D, Benzaid A, et al. Corrosion Sci. 2008;50:1841.

40. Petrović MB, Radovanović MB, Simonović AT, et al. Int J Electrochem Sci. 2012;7:9043.

41. Ashassi-Sorkhabi H, Asghari E. J Appl Electrochem. 2010;40:631.

42. Yurt A, Ulutas S, Dal H. Appl Surf Sci. 2006;253:919.

43. Lashgari M, Malek AM. Electrochim Acta. 2010;55:5253.

44. Halambek J, Berkovic K, Fura JV. Mater Chem Phys. 2013;137:788.

45. Niu L, Cheng YF. Wear. 2008;367.

46. Wang B, Zhang L, Su Y, et al. Mater Des. 2013;50:15.

47. Hassan RM, Zaafarany IA. Materials. 2013;6:2436-2451.

48. Prabhu D, Rao P. Arabian J Chem. 2017;10:s2234.

49. Abiola OK, Otaigbe JOE. Corrosion Sci. 2009;51:2790.

50. Pyun S-I, Moon S-M. J. Solid State Electrochem. 2000;4:267.

51. Moon S-M, Pyun S-I. J. Solid State Electrochem. 1999;3:104.

52. Ashassi-Sorkhabi H, Majidi MR, Seyyedi K. Appl Surf Sci. 2004;225:176.

53. Fu J-j, Li S-g, Wang Y, et al. J Mater Sci. 2010;45:6255.

54. Oguzie EE, Li Y, Wang FH. J Colloid Interface Sci. 2007;310:90.

55. Gudić S, Smoljko I, Kliškić M. J Alloy Compd. 2010;505:54.

56. Frers SE, Stefenel MM, Mayer C, et al. J Appl Electrochem. 1990;20:996.

57. Rehim SSAE, Hassan HH, Amin MA. Mater Chem Phys. 2001;70:64. 
58. Gojic M, Horvat R, Metikos-Hukovic M. Proceedings of the Eight ${ }^{\text {th }}$ European Symposium on Corrosion Inhibitors (8 SEIC). Ann Univ Ferrrara; 1995.

59. Frichet A, Gimenez P, Keddam M. Electrochim Acta. 1993;38:1957.

60. Saifi H, Bernard MC, Joiret S, et al. Corrosion Sci. 2010;120:661.

61. Otmačić H, Stupnišek-Lisac E. Electrochim Acta. 2003;48:985.

62. Ferreira ES, Giacomelli C, Giacomelli FC, et al. Mater Chem Phys. 2004;83:129.

63. Khavani M, Izadyar M, Housaindokht MR. Phosphorus, Sulfur, and Silicon and the Related Elements. 2015.

64. Ralph TR, Hitchman ML, Millington JP, et al. J Electroanal Chem. 1994;375:1.

65. Kendall E, Nord F. J Biol Chem. 1926;69:295.

66. Muzaffer Ö. J Solid State Electrochem. 2008;12:1653.

67. Morad MS. J Appl Electrochem. 2008;38:1509.

68. Aouniti A, Khaled KF, Hammouti B. Int J Electrochem Sci. 2013;8:5925.

69. Hluchan V, Wheeler BL, Hackerman N. Werkst Korros. 1988;39:512.

70. Gutz IGR. CurTiPot. http://www.iq.usp.br/gutz/Curtipot.html, 2016.

71. Simonović AT, Petrović MB, Radovanović MB, et al. Chem Pap. 2014;68:362.

72. Kovačević N, Kokalj A. Corrosion Sci. 2011;53:909. 